\title{
Editorial:
}

\section{Aging and the Humanities}

The Humanities in Gerontology comprise a substantial and varied subject matter. There are now extant in the literature several texts which attempt to provide a representation of various disciplines concerned with aging. Contributions originate in History, Literature, Philosophy, Theology, Fine Arts, Anthropology and others. In particular, the reader is referred to two volumes recently published which provide an excellent source of scholarship related to the Humanities in Gerontology.

The first volume is entitled The Handbook of the Humanities and Aging (Cole, Van Tassel, \& Kastenbaum, 1992) and the second Voices and Visions of Aging (Cole, Achenbaum, Jakobi, \& Kastenbaum, 1993). These volumes not only introduce areas of Humanities Scholarship in Gerontology, but also provide further references for specific areas of interest. There is, however, one important criticism which I would like to direct to these volumes, and that is that the authors are all American. This situation is quite acceptable; however, it must be mentioned that these volumes do not represent all there is to know about the Humanities in Gerontology. While space does not permit a listing of contributors, good work is being done in Europe, Scandinavia and Canada in this area. In my view, in this postmodern world to which many authors refer, we need to have as large a "voice and vision" as possible.

This criticism notwithstanding, it is a challenging task to organize a volume such as those just mentioned, or a special issue that deals with this broad and diverse subject matter. In the case of this special issue, the process of the Journal formed the basis of manuscript selection. That is, while a number of papers were invited in the first instance, this was supplemented by a call for papers, all of which were subjected to the usual review process. I mention this to emphasize that this special issue contains a series of manuscripts that focus on particular aspects of the humanities and aging. The importance and value of this scholarship emerges from the specific contribution that each article makes to our understanding of aging.

However, having said this, there is a generalizable contribution that can be identified. Each paper, in its own way, provides a reflection on the way in which we as researchers, policy-makers, practitioners and persons make decisions in our areas of expertise in the field of aging. The humanities explores the hermeneutic dimension of knowledge by questioning the values, assumptions and metaphors with which we all work, either implicity or explicity (Kenyon, Birren, \& Schroots, 1991). By providing this self-reflective dimension, the Humanities in Gerontology contribute to the overall agenda to have our understanding of aging reflect all aspects of human nature; namely, physical, psychological, social, and spiritual-existential. A further contribution is that of informing our praxis with an ethical dimension; in other words, humanizing our systems, by providing a broad forum that is 
inclusive of and complementary to political, economic, and other forms of reasoning (Kenyon \& Davidson, 1993).

There are six contributions comprising this special issue. The first four papers focus on individual or personal aging and the remaining two papers emphasize social structural aspects of aging that ultimately impact on individual aging.

The papers by Harrison, Boetzkes, and Checkland and Silberfeld are concerned with the crucial constellation of concepts of autonomy, competence and personhood. These notions form the basis for intervention decisions in the field of aging. The dialogue in this context involves mainly the disciplines of medicine, ethics, and law. However, in addition to these disciplines, the three papers argue for a move beyond the philosophical and technical discussion of definitions to the manner in which we might better apply notions of competence and autonomy to individual real lives. There is a distinctly ontological aspect to these articles, that is, they urge us to explicitly acknowledge the self-creating, meaning-giving aspect of human nature. For Harrison and Boetzkes, a very effective way to accomplish this objective is through a focus on biographies and the narrative dimension of human lives. For Boetzkes, this approach will assist in minimizing the external constraints and possible coercion in deciding to complete an advance health care directive. In the case of Harrison, a focus on narrative will obviate the tendency to forget that a dementing person remains a person with moral worth and that they still have a story to tell. This view encourages us to look at losses, but also at what strengths a person continues to possess. The point here is that this is a highly idiosyncratic and dynamic situation requiring personalized interventions which are accessible through biographical materials. (For further discussion of theoretical and practical issues pertaining to aging and biography, see Birren, Kenyon, Ruth, Schroots, \& Svensson (in preparation).)

Checkland and Silberfeld are also concerned with a contextual focus for intervention, with an emphasis on the distinction between autonomy and competence. Their basic argument is that a decision-specific basis for competence will take us further than general attempts at defining such things as autonomy. While they do not discuss narratives and biography, they do argue for a dynamic and idiosyncratic assessment of competence based on such things as changing "patterns of authenticity," and I would add, sources of meaning. An interesting aspect of all these papers is that the discussion applies to both competent and incompetent older persons. Incompetence does not remove personhood.

The paper by Manning gives us insight into existential-spiritual aspects of aging. For Manning, literature can contribute to our understanding of aging through "imaginative fictions and lyrical evocations of experience". These products of the imagination can be seen to apply to real lives and real situations and, therefore, provide another source of knowledge for research and practice in Gerontology. In particular, Manning urges us to look beyond physical frailty to the possibility that a disengaged older person may 
have transcended his/her frailty in very meaningful ways. One could say that, in this sense, a frail older person may have so little, but be so much.

In the fifth and sixth papers, the focus shifts from individual aging per se to an emphasis on structural-systematic relationships that also define the experience of aging. In the fifth article, Phillip Clark indicates that, ultimately, the assumptions and values that guide public policy procedures and decisions significantly influence individual aging through such things as the degree of ageism reflected in various policies and the implications this has for quality of life. In addition, public policy assumptions also influence the way people internalize their own aging, for example, as a problem or celebration. By way of a comparison between the current situation in Canada and the United States, Clark argues that what is required, and lacking especially in the United States, is a "public ethics" whereby aging and such things as autonomy in aging are subjected to a community-oriented dialogue. In this way, a balance can be achieved between, on the one hand, individual rights and responsibilities, and, on the other hand, societal responsibility for autonomy in a civilized country. For Clark, older persons need to be truly empowered to frame public policy decisions and solutions.

In the final article, James Snell takes up, by way of an historical analysis, another structural aspect of aging. He points to an example of the way gender inequality has been systematically supported by old age pension policies in Canada. Snell argues that basic beliefs about marriage took precedence over the needs of individual older persons, women in particular. For Snell, the state created a significant degree of dependency on the part of older women. It is interesting to note that the paper by Snell provides a further instance of the need for a "public ethics" form of reasoning urged by Clark.

As a final editorial remark, the humanities contribute to the "Logos" or story of aging by providing a vehicle to test the soundness of our systematic approaches to science and practice. By soundness is meant the degree to which our scientific methods and technical training are responsive to the lived experience of aging persons, and the meaning that those persons attribute to that experience. (In addition to the papers in this volume, see also Haldemann, 1993, for a recent related discussion of Qualitative Methods in Gerontology.)

\section{References}

Birren, J., Kenyon, G., Ruth, J.E., Schroots, J.J.F., \& Svensson, T. (Eds.). (in preparation). Aging and Biography: Explorations in Adult Development. New York: Springer.

Cole, T., Achenbaum, A., Jakobi, P., \& Kastenbaum, R. (Eds.). (1993). Voices and Visions of Aging. New York: Springer.

Cole, T., Van Tassel, D., \& Kastenbaum, R. (Eds.). (1992). Handbook of Humanities and Aging. New York: Springer. 
Haldemann, V. (Ed.). (1993). Qualitative Methods: Why? Canadian Journal on Aging, Special Issue, 12(2): 117-138.

Kenyon, G., Birren, J., \& Schroots, J.J.F. (Eds.). (1991). Metaphors of Aging in Science and the Humanities. New York: Springer.

Kenyon, G., \& Davidson, W. (1993). Ethics in An Aging Society. In Ethics and Aging, Writings in Gerontology, Number 13. Ottawa: National Advisory Council on Aging.

Gary M. Kenyon, St. Thomas University 